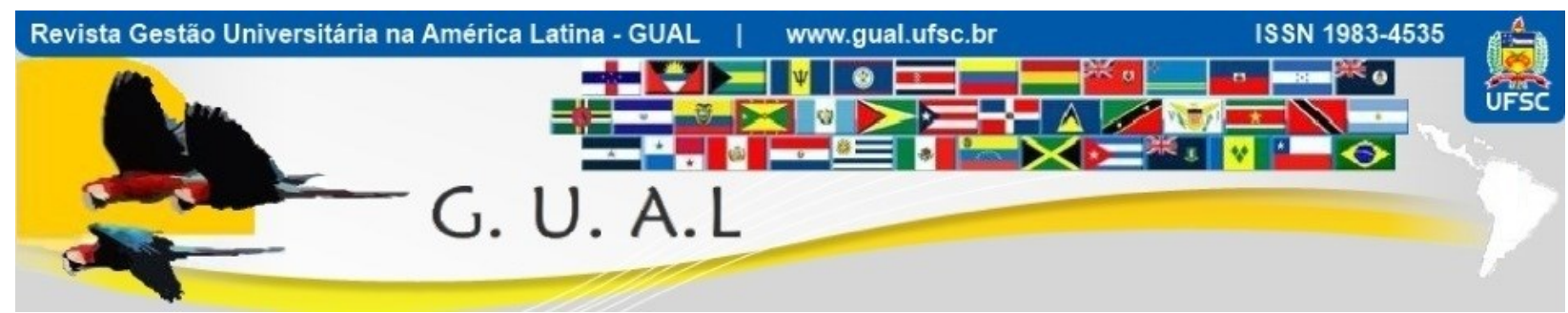

DOI: http://dx.doi.org/10.5007/1983-4535.2016v9n4p146

\title{
A DINÂMICA DO CONHECIMENTO NA CONSTRUÇÃO DE UMA UNIVERSIDADE EMPREENDEDORA: POTENCIALIDADES E FRAGILIDADES OBSERVADAS NA UNIVERSIDADE FEDERAL DE PERNAMBUCO
}

\section{THE DYNAMICS OF KNOWLEDGE IN CONSTRUCTING AN ENTREPRENEURIAL UNIVERSITY: THE POTENTIALITIES AND WEAKNESSES OBSERVED AT THE FEDERAL UNIVERSITY OF PERNAMBUCO}

Paulo Sergio Oliveira do Nascimento, Mestre Universidade Federal de Pernambuco - UFPE nascpaulo@gmail.com

Jonathan Félix de Carvalho, Mestre Universidade Federal de Pernambuco - UFPE jonathan.fcarvalho@hotmail.com

Alexsandra Barbosa de Souza Cyreno, Mestre Universidade Federal Rural de Pernambuco - UFRPE alesouza2012@hotmail.com

Denilson Bezerra Marques, Doutor Universidade Federal de Pernambuco - UFPE marquesdb@gmail.com

Recebido em 04/dezembro/2015

Aprovado em 14/outubro/2016

Sistema de Avaliação: Double Blind Review

Esta obra está sob uma Licença Creative Commons Atribuição-Uso. 


\title{
A DINÂMICA DO CONHECIMENTO NA CONSTRUÇÃO DE UMA UNIVERSIDADE EMPREENDEDORA: POTENCIALIDADES E FRAGILIDADES OBSERVADAS NA UNIVERSIDADE FEDERAL DE PERNAMBUCO \\ DOI: http://dx.doi.org/10.5007/1983-4535.2016v9n4p146
}

\section{RESUMO}

O presente estudo visa refletir sobre potencialidades e fragilidades para o surgimento de uma Universidade Empreendedora, com base, principalmente, em pesquisas realizadas na Universidade Federal de Pernambuco (UFPE) em 2013 e 2015. Destaca-se aqui a produção e disseminação do conhecimento, a inovação, a sociedade do conhecimento, a gestão e a burocracia como elos estruturadores da relação acadêmica e institucional com o mercado e a sociedade. Aborda-se, para tanto, a dinâmica do conhecimento e sua relevância no contexto da globalização e da atual sociedade, bem como as transformações que afetam o Estado e redefinem o seu papel. A metodologia adota uma abordagem qualitativa com a técnica de estudo de caso, valendo-se de análise de dados, a partir da análise argumentativa de Toulmin (2001) aplicada nas pesquisas supramencionadas. Os achados desta reflexão evidenciam a pertinência e atualidade dos estudos de Henry Etzkowitz (2009), sobre a relação Universidade-Indústria-Governo (hélice tríplice), e Peter Evans (2004), atinente à estrutura de Estado e relação Estado-Sociedade, ao explicarem aspectos importantes do processo de desenvolvimento econômico e social.

Palavras-chave: Conhecimento. Sociedade do conhecimento. Universidade empreendedora. Burocracia. Inovação.

\begin{abstract}
The present study aims to reflect on the potentialities and weaknesses for the emergence of an Entrepreneurial University, based primarily on research conducted at the Universidade Federal de Pernambuco (UFPE) in 2013 and 2015. We set out herein to highlight the production and dissemination of knowledge, innovation, knowledge society, management and bureaucracy as the structural links of the academic and institutional relationship with both the market and society. We therefore address the dynamics of knowledge and its relevance within the context of globalization and current society, as well as the changes that affect the state and redefine its role. The study adopted a qualitative case study methodology, drawing on data analysis using the Toulmin model of argumentation (2001) applied to the abovementioned research. The findings of this reflection highlight the relevance and topicality of the studies by Henry Etzkowitz (2009) on the university-industry-government (Triple Helix) relationship, and Peter Evans (2004) regarding state structures and state-society relations, in explaining key aspects in the process of economic and social development.
\end{abstract}

Keywords: Knowledge. Knowledge society. Entrepreneurial University. Bureaucracy. Innovation. 


\section{A DINÂMICA DO CONHECIMENTO NA CONSTRUÇÃO DE UMA UNIVERSIDADE EMPREENDEDORA: POTENCIALIDADES E FRAGILIDADES OBSERVADAS NA UNIVERSIDADE FEDERAL DE

\section{INTRODUÇÃO}

De acordo com Baumgarten, Teixeira e Lima (2007), atualmente o conhecimento desempenha um papel estratégico, não só para a acumulação econômica, mas também para o funcionamento do próprio Estado e da sociedade. Isso porque, diante da velocidade das inovações e da complexidade do mundo atual, as redes de produção, disseminação e apropriação de conhecimentos passam a desempenhar papel central nas sociedades. Esse caráter estratégico demanda reflexões sobre elementos centrais e sobre as repercussões que trazem para as formas de produção e apropriação de conhecimentos (BAUMGARTEN; TEIXEIRA; LIMA, 2007).

Em face de tais indagações, o presente estudo objetiva refletir como a dinâmica do conhecimento se revela nas relações institucionais praticadas por uma Instituição Federal de Ensino Superior (IFES), a UFPE, no que concerne ao seu papel de empreendedorismo e inovação, observando potencialidades e fragilidades apontadas pelos estudos de Santos (2013) e Lacerda (2015). Os aludidos trabalhos apresentam percepções de gestores da Refinaria Abreu e Lima e do Polo Tecnológico de Fármacos e Biociências, projetos industriais estruturadores localizados no estado de Pernambuco, em relação às parcerias desenvolvidas com a Universidade.

Para apresentar objetivamente - porém de forma aprofundada - essa temática, além dessa breve introdução, este trabalho se estrutura em mais oito seções. Inicialmente, faz-se uma discussão sobre a relevância do conhecimento para a transformação e desenvolvimento das sociedades na trajetória histórica das civilizações. Seu papel estratégico para o avanço das tecnologias, nos processos de trabalho e na acumulação econômica.

A partir desse contexto, discute-se sobre o que se entende por sociedade do conhecimento e sobre a forma na qual se estabelece a lógica complexa do desenvolvimento, nesse cenário de mudanças contínuas nos campos econômico, social e tecnológico.

Aborda-se, em seguida, o posicionamento da instituição universitária como produtora, disseminadora e indutora de conhecimento e inovação, seu papel empreendedor e central na hélice tríplice, definida por Etzkowitz (2009).

O avanço nesse debate leva a um esforço no sentido de demonstrar, com base principalmente nas definições de Evans (2004), a importância do papel do Estado e de sua burocracia na universidade empreendedora. 


\section{A DINÂMICA DO CONHECIMENTO NA CONSTRUÇÃO DE UMA UNIVERSIDADE EMPREENDEDORA: POTENCIALIDADES E FRAGILIDADES OBSERVADAS NA UNIVERSIDADE FEDERAL DE

Não obstante, também se faz uma caracterização da gestão no âmbito das Instituições de Ensino Superior, observando na realidade atual dessas organizações, fatores cruciais de desempenho, além de capacidades técnicas necessárias para a qualidade da gestão.

Adiante se explica a metodologia adotada na pesquisa. E, por fim, as duas últimas seções, o caso da UFPE e considerações, são a análise propriamente dita dos achados da pesquisa.

\section{CONHECIMENTO}

O surgimento da escrita, desde os tijolos de barro ou pedaços de cerâmica (Babilônia), pergaminho (Ásia Menor), papiro (Egito), até chegar ao papel (China), facilitou a transmissão da cultura. Essa evolução de procedimentos culminou com o aparecimento da imprensa, que produz um número maior de informações, disseminando-as em grande escala (CARVALHO, KANISKI, 2000; GORDON, 2001).

O conhecimento possui uma relevância com dimensões que progridem ao decorrer do tempo. Segundo Stewart (1998, p. 5) "o conhecimento sempre foi importante - não é à toa que somos o homo sapiens, o homem que pensa". Tal importância já era percebida desde as primeiras civilizações, as quais, através das grandes bibliotecas, preocupavam-se em preserválo, recolhendo-o, armazenando-o e distribuindo-o de forma eficiente e eficaz (GORDON, 2001).

Com o desenvolvimento tecnológico, a sociedade passou a vivenciar várias invenções e descobertas, conduzindo-a a uma nova forma de se organizar, produzir e comunicar (SORDI, 2008; NONAKA; TAKEUCHI, 1997). Através desse processo, a sociedade experimenta uma grande difusão de inovações. Para Cassiolato (1999, p. 164) “(...) evidenciase uma mudança de paradigma das tecnologias intensivas em capital e energia e de produção inflexível e de massa para as tecnologias intensivas em informação, flexíveis e computadorizadas”. Esse é um marco fundamental que revela o grande avanço das pesquisas científicas.

Observa-se, portanto, que o advento da Tecnologia da Informação e Comunicação (TIC) trouxe grandes transformações na estrutura econômica da sociedade pós-industrial. Essas transformações atingiram todos os níveis e instâncias da economia, sob a égide da incorporação do conhecimento, como elemento que agrega valor aos produtos/serviços disponibilizados à sociedade (ANGELONI, 2003; COELHO, 2004). 


\section{A DINÂMICA DO CONHECIMENTO NA CONSTRUÇÃO DE UMA UNIVERSIDADE EMPREENDEDORA: \\ POTENCIALIDADES E FRAGILIDADES OBSERVADAS NA UNIVERSIDADE FEDERAL DE \\ DOI: http://dx.doi.org/10.5007/1983-4535.2016v9n4p146}

Stewart (1998, p. xiii) nota que “a informação e o conhecimento são armas termonucleares competitivas de nossa era". Entende-se, portanto, que o sucesso e a diferenciação no mercado ficarão estabelecidas para as empresas que melhor utilizarem as informações ou para as que conseguirem geri-las de forma mais eficaz (STEWART, 1998).

Corroborando com essa linha de pensamento, Drucker (2002) ressalta que a organização que melhor conduzir todo o aprendizado adquirido ao longo do tempo, empregando a inovação e a criação, de forma sistematizada, no local de trabalho, terá um melhor rendimento organizacional.

De acordo com Baumgarten, Teixeira e Lima (2007, p. 402): “o conhecimento desempenha, atualmente, papel estratégico, não só para a acumulação econômica, mas também para o funcionamento do próprio Estado e da sociedade”. Esses autores acreditam que a produção do conhecimento repercute em diversas atividades, o que possibilita o trabalho inter e transdisciplinar em um contexto cada vez mais globalizado. É necessário que as pessoas acompanhem tais mudanças, sob pena de ficarem de fora desse processo, pois a tecnologia sozinha não garante o conhecimento, alertam Silva, Correia e Lima (2010).

Segundo Calle e Silva (2008), o reflexo dessa transformação impacta diretamente no desenvolvimento dos países, tendo o conhecimento como mola propulsora. Nesse contexto, também devem ser levados em consideração a conjuntura do crescimento, a globalização e os avanços tecnológicos que afetaram a produção/serviços e a comunicação/informação. Tal dinâmica exige uma visão estratégica tanto por parte dos representantes do setor produtivo quanto por parte dos representantes do Estado, pois impacta no processo da aprendizagem e eleva o patamar dos conhecimentos gerados e empregados pela sociedade moderna, possibilitando maior competitividade e ganhos sociais e econômicos reais para esta sociedade (WERTHEIN, 2000; SILVA, 2002; BESSA; NERY; TERCI, 2003; BORGES, 2008; CALLE; SILVA, 2008; CASTELLS, 2011).

\section{SOCIEDADE DO CONHECIMENTO}

De acordo com Neto e Teixeira (2006) a sociedade do conhecimento e da informação traz grandes alterações para a relação entre a economia e a sociedade, salientando a importância desta mudança para a cadeia produtiva. Para Souza (2006), essa transformação, que atinge a sociedade, se distingue pela incerteza e complexidade, dependendo da geração de novos conhecimentos de forma contínua. 


\section{A DINÂMICA DO CONHECIMENTO NA CONSTRUÇÃO DE UMA UNIVERSIDADE EMPREENDEDORA: \\ POTENCIALIDADES E FRAGILIDADES OBSERVADAS NA UNIVERSIDADE FEDERAL DE PERNAMBUCO \\ DOI: http://dx.doi.org/10.5007/1983-4535.2016v9n4p146}

$\mathrm{Na}$ sociedade do conhecimento, o saber não é fragmentado, os conteúdos são utilizados de forma inter-relacionada, não existindo fronteiras delimitadas para o conhecimento. Essa lógica impacta numa interdependência de fatores em diversas áreas da ciência, desde a biologia à microeletrônica, tanto em relação a materiais quanto a métodos (CASTELLS, 1992, 2011). Nessa condição, segundo Choo (2006, p. 30): “a organização que for capaz de integrar eficientemente os processos de criação de significado, construção do conhecimento e tomada de decisões pode ser considerada uma organização do conhecimento". O que faz refletir sobre a necessidade de as organizações estarem atentas a um modelo de pensamento sistêmico organizacional, no qual possam integrar um corpo coeso de teoria e prática, imbuídas da capacidade de aprender (SENGE, 2006).

Gorz (2005, p. 9) considera que "na economia do conhecimento, todo trabalho, seja na produção industrial seja no setor de serviços, contém um componente de saber cuja importância é crescente". Esse conhecimento está fundamentado na experiência, no discernimento, na capacidade de coordenação, de auto-organização e comunicação (STEWART, 1998; CARTONI, 2006).

A nova era, denominada sociedade do conhecimento, que traz o saber como base econômica e social para o desenvolvimento de tecnologias avançadas, aponta a integração da universidade, indústria e governo como arranjo ideal (ETZKOWITZ, 2009). Nesse novo contexto, o autor $(2009$, p.1) ressalta que "a universidade é o princípio gerador das sociedades fundadas no conhecimento, assim como o governo e a indústria são instituições primárias na sociedade industrial". É a instituição responsável por formar o capital humano, considerado como o diferenciador do processo.

\section{UNIVERSIDADE E SEU PAPEL EMPREENDEDOR}

A universidade é uma organização quase milenar, que, segundo Todescat e Santos (2006, p.1) representa “a mola propulsora das grandes mudanças sociais, econômicas, culturais, ambientais e tecnológicas, que repercutem no desenvolvimento da sociedade".

Segundo Etzkowitz (2009), mesmo que a universidade venha a desempenhar atividades que, a princípio, deveriam ser desenvolvidas pelo governo e pelas empresas, ela não deixará de executar a sua função principal que é de conservar, produzir e disseminar o conhecimento. 


\section{A DINÂMICA DO CONHECIMENTO NA CONSTRUÇÃO DE UMA UNIVERSIDADE EMPREENDEDORA: \\ POTENCIALIDADES E FRAGILIDADES OBSERVADAS NA UNIVERSIDADE FEDERAL DE PERNAMBUCO \\ DOI: http://dx.doi.org/10.5007/1983-4535.2016v9n4p146}

Ainda de acordo com Etzkowitz (2009) o empreendedorismo faz parte do ensino e da pesquisa, na perspectiva da missão acadêmica. A universidade, nesta condição, se aproxima do setor industrial. Como corolário, a incubadora assume um papel relevante no intuito de conduzir a missão educacional, modificando o formato tradicional acadêmico e desenvolvendo o ensino de pessoas em ensino de organizações (ETZKOWITZ, 2009). O mesmo autor também compreende que uma universidade empreendedora deve estar embasada em quatro pilares: a) Liderança acadêmica; b) Controle jurídico sobre os recursos acadêmicos; c) Capacidade organizacional; d) Um ethos empreendedor entre administradores, corpo docente e estudantes.

Audy e Ferreira (2006, p. 420) afirmam que "o conceito de universidade empreendedora se refere a uma postura pró-ativa das instituições no sentido de transformar conhecimento gerado em agregação de valor econômico e social”. Surge para atender as necessidades da sociedade atual, estando intrínsecos elementos relevantes tais como: inovação, criatividade e risco. A universidade tem que ocupar seu espaço de protagonista e adaptar-se a esse novo momento transformador da sociedade. Nesse novo cenário, frente a problemas complexos e incertezas, as universidades passam a ser mais cobradas e a sociedade passa a esperar mais delas, em termos de contribuições ao processo de desenvolvimento econômico e social (AUDY, 2006).

Segundo Etzkowitz (2009, p. 37), está na égide de uma nova missão para a universidade a "capitalização do conhecimento". Tal fenômeno se traduz na conexão aos usuários do conhecimento de forma mais próxima, o que permitirá que a universidade se estabeleça como um ator econômico por mérito próprio. Só assim ela assumirá um papel preponderante na busca de soluções para as demandas da sociedade, impulsionando um desenvolvimento sustentável (SOUZA, 2006).

Para Casado, Siluk e Zampieri (2012, p. 633): “as universidades, como criadoras e disseminadoras de conhecimento, constituem-se em potenciais agentes de práticas de desenvolvimento sustentável e responsabilidade social". Corroborando com essa ideia, Etzkowitz (2009) sustenta que, ao contrário de outras teorias que ressaltam o papel do governo ou das empresas na inovação, na hélice tríplice a universidade é o centro do processo empreendedor e tecnológico, destacando-se pelo método das investigações críticas.

A hélice tríplice, cunhada por Etzkowitz na década de 90, consiste na relação de três espirais que representam Governo-Empresa-Universidade. O movimento tem início quando 


\section{A DINÂMICA DO CONHECIMENTO NA CONSTRUÇÃO DE UMA UNIVERSIDADE EMPREENDEDORA: POTENCIALIDADES E FRAGILIDADES OBSERVADAS NA UNIVERSIDADE FEDERAL DE PERNAMBUCO \\ DOI: http://dx.doi.org/10.5007/1983-4535.2016v9n4p146}

essas três esferas resolvem atuar em conjunto para desenvolver um projeto, visando à inovação tecnológica, a produção de conhecimentos e o desenvolvimento econômico. A partir da decisão, cada elemento trabalhará para facilitar as atividades que estarão sob sua gestão, interferindo direta e positivamente no resultado final. Geralmente, um dos espirais fica no centro, comandando as tarefas e, em torno dele, agem os demais para auxiliar na execução da atividade. Tal estrutura vai mudando de acordo com a afinidade entre a esfera e o projeto a ser executado ou problema a ser resolvido (ETZKOWITZ, 2009).

\section{O PAPEL DO ESTADO E DA BUROCRACIA NA UNIVERSIDADE EMPREENDEDORA}

A inovação, na forma de atuação trazida pela hélice tríplice, acarreta novos arranjos institucionais. Como corolário, cabe ao Estado uma nova postura frente a inúmeras transformações sociais e econômicas, potencializadas com a globalização que transforma bruscamente a lógica do setor produtivo (ABRUCIO, 2006). Isso implica dizer que é papel do Estado criar condições para que essa interação ocorra de forma a colaborar para um objetivo maior, que é capacitar tecnologicamente o sistema produtivo, ao mesmo tempo também se constitui como seu papel a manutenção de tais condições, para com isso se estabelecer um círculo virtuoso e sustentável da lógica do desenvolvimento nas esferas econômica e social.

Tal contexto é muito bem discutido por Evans (2004), ao caracterizar as diferentes formas de estrutura do Estado e de relações Estado-Sociedade em dois tipos historicamente idealizados: 1) Estados predadores; 2) Estados desenvolvimentistas.

Os Estados predadores conseguem, às custas da sociedade, refrear deliberadamente o processo de desenvolvimento, mesmo em sua dimensão mais estreita de acumulação de capital. Os Estados desenvolvimentistas, por sua vez, não apenas direcionam a transformação industrial, mas também, como pode ser argumentado de forma plausível, são em grande parte responsáveis pelo desenvolvimento (EVANS, 2004, p. 37).

Os Estados predatórios são caracterizados por uma carência de burocracia, como definiu Max Weber ${ }^{1}$. Esta argumentação se fundamenta numa abordagem institucional

\footnotetext{
${ }^{1} \mathrm{O}$ modelo burocrático weberiano é um modelo organizacional que desfrutou notável disseminação nas administrações públicas durante o século XX em todo o mundo. É atribuído a Max Weber, porque o sociólogo alemão analisou e sintetizou suas principais características. Foi implementado no Brasil a partir da década de 1930, no Governo de Getúlio Vargas, através do Departamento Administrativo do Serviço Público - DASP (ABRÚCIO, 2006)
} 


\section{A DINÂMICA DO CONHECIMENTO NA CONSTRUÇÃO DE UMA UNIVERSIDADE EMPREENDEDORA: POTENCIALIDADES E FRAGILIDADES OBSERVADAS NA UNIVERSIDADE FEDERAL DE

comparativa, que aponta a escassez de burocracia como fator impeditivo para o desenvolvimento, ao ser confrontado com a de diferentes agências governamentais de outros países. Essas diferenças são visualizadas na forma como os países foram estruturados, pelo fato de haverem vários graus de desenvolvimento alcançados e de sua relação com a sociedade (EVANS, 2004).

Evans (2004) ainda identifica quatro papéis desempenhados pelo Estado. O primeiro deles é o "custódio", relacionado ao papel regulador do Estado, através da prática de políticas fiscais, por exemplo. O segundo, "demiurgo", refere-se à atuação do ente político como produtor, responsabilizando-se pela produção de bens de interesse público e que favorece o desenvolvimento. Já o "parteiro" auxilia o surgimento de novos segmentos, novas empresas, atuando através de políticas protecionistas e de incentivos. E, por fim, o "pastor", que focaliza não só o suporte, como também estimula a implantação de novas empresas. Observa-se que os dois últimos estão voltados para a parceria entre agências estatais e grupos empresariais privados.

Para Evans (2004, p. 37-38): “a organização interna dos Estados desenvolvimentistas assemelha-se mais à burocracia weberiana", que necessita de um certo tipo de "autonomia". Acrescenta ainda que a implantação do Estado desenvolvimentista requer uma composição entre a autonomia e a inclusão de interesses coletivos. Sem esta condição, a autonomia e a inserção dos interesses iriam funcionar de forma isolada (EVANS, 2004).

Nesse contexto, a burocracia estatal deve estar inserida para assegurar a eficiência da relação com a sociedade, ao invés de se isolar. O Estado e as estruturas sociais são fatores mutuamente determinantes em relação à autonomia e à inserção social. Assim, as novas formas de relações sociais devem acontecer dessa maneira, visto que o mercado também não opera de forma isolada (EVANS, 2004).

Castells e Cardoso (2005, p. 27) defendem que "o setor público é atualmente o ator decisivo para desenvolver e moldar a sociedade em rede. Indivíduos inovadores, comunidades contraculturais e empresas de negócios, já fizeram o seu trabalho ao inventar uma nova sociedade e ao difundi-la por todo o mundo". Convergindo com esse raciocínio, Evans (2004, p. 59) afirma que "a superioridade do Estado burocrático moderno está em sua habilidade de superar a lógica individualista”. E identifica ainda que:

Caso uma máquina administrativa eficiente seja estabelecida, é possível que ocorra tanto sua dissolução e decadência quanto sua expansão e fortalecimento. Se a 


\section{A DINÂMICA DO CONHECIMENTO NA CONSTRUÇÃO DE UMA UNIVERSIDADE EMPREENDEDORA: POTENCIALIDADES E FRAGILIDADES OBSERVADAS NA UNIVERSIDADE FEDERAL DE

transformação exige uma burocracia eficiente, não há nenhuma garantia de que a oferta vá atender a demanda. A abordagem institucional comparativa inverte a imagem neo-utilitarista do Estado. É a insuficiência de burocracia que prejudica o desenvolvimento, e não sua prevalência (EVANS, 2004, p. 71).

Com relação ao foco deste trabalho, Saraiva (2002, p. 192) argumenta que "dentro do universo de organizações burocráticas, a universidade em si possui uma problemática complexa em termos organizacionais, pois ora é tratada como tipo especial de burocracia, ora como tipo similar às demais organizações burocráticas".

\section{A GESTÃo NO ÂMBITO DAS UNIVERSIDADES: ASPECTOS RELEVANTES PARA OS RESULTADOS INSTITUCIONAIS}

Diante da afirmação, a seguir, de Santos (2013, p. 106): “a burocracia busca a adequação dos meios aos objetivos pretendidos a fim de garantir a máxima eficiência das organizações; com a adoção de mudanças e uma maior atenção aos aspectos apontados" verifica-se a importância da atuação dos gestores nesse processo, já que são responsáveis por gerir pessoas para o atingimento de metas e objetivos da instituição.

No atual cenário, que concede lugar de destaque para o conhecimento e a inovação, as pessoas passam a ser primordiais para o sucesso das instituições. Voltado para o contexto público, Pereira et al. (2015) ressalta a importância dos indivíduos, defendendo que a principal atividade do Estado é satisfazer as necessidades do coletivo, atribuição que é realizada por servidores públicos, considerados atores imprescindíveis para qualquer mudança de grande impacto na atividade pública. Se for levado em consideração, especificamente, a instituição de ensino superior, cujo produto está voltado ao conhecimento, observa-se que o fator humano é essencialmente a base da produção, o gerador do conhecimento (TOSTA et al., 2012).

Cartoni (2006, p. 98) afirma que "a mudança do paradigma industrial para o paradigma do conhecimento ou da onda industrial para a onda do conhecimento, exige também mudança na forma de se gerenciar as organizações”. À medida que o conhecimento é mais valorizado, aumenta a necessidade de geri-los como ativos intangíveis que são.

Assim sendo, observa-se que os gestores possuem um papel fundamental como facilitadores dessa nova atuação. O presente cenário requer das instituições públicas em todas as esferas (federal, estadual e municipal) uma performance distinta, e o estilo de gestão tem papel decisivo para que esse novo nível de exigência possa ser alcançado (ÉSTHER, 2011). 


\section{A DINÂMICA DO CONHECIMENTO NA CONSTRUÇÃO DE UMA UNIVERSIDADE EMPREENDEDORA: POTENCIALIDADES E FRAGILIDADES OBSERVADAS NA UNIVERSIDADE FEDERAL DE

Dessa forma, pode-se associar o êxito de uma instituição, sobretudo, ao bom desempenho dos seus gestores, já que eles são responsáveis não só pela definição dos objetivos institucionais, como também por todos os procedimentos para alcançá-los. Diante do exposto, verifica-se a importância de gerentes que possuam competências para gerir as variáveis envolvidas em todo o processo, relacionadas não só aos recursos técnicos e administrativos, mas, principalmente, às pessoas (SANTANA; MAIA, 2014).

Observa-se, porém, que a maioria dos gestores universitários são docentes, os quais nem sempre possuem capacitação técnica para desempenhar as atividades envolvidas no cargo. Por isso, as instituições de ensino superior precisam investir no desenvolvimento contínuo de competências que potencializem a atuação dos gestores (PEREIRA et al, 2015); levando em consideração a conjuntura atual de rápidas mudanças, inúmeras informações e ações cada vez mais inter-relacionadas com a sociedade, o mercado e o governo. Reforçando esse entendimento, Tosta et al. (2012) afirmam que para os gestores universitários atuarem de forma efetiva, atendendo as exigências do contexto contemporâneo, precisam desenvolver seus conhecimentos nessa área.

A ausência de gestores com as competências necessárias pode acarretar, conforme identificado por Santos (2013), uma fragilidade na gestão, interferindo negativamente nos resultados da instituição. Já que ações intrínsecas à função estarão prejudicadas, tais como: planejamento do alcance de objetivos institucionais; acompanhamento eficiente e eficaz de projetos e obras; delegação de ações e de poder decisório; aquisição de materiais e equipamentos; e administração de recursos financeiros, humanos e de infraestrutura.

Com relação às instituições de ensino superior, observa-se que o desenvolvimento de competências gerenciais pode ser realizado na sua própria estrutura, por se tratar de um centro de excelência no desenvolvimento e transmissão do conhecimento. Tal desenvolvimento deve facilitar a atuação dos gestores para, consequentemente, trabalharem através da burocracia, a qual interfere positivamente para o bom resultado da instituição, o que reforça a hipótese de Evans (2004) sobre a importância da burocracia inserida na promoção do desenvolvimento sustentável e duradouro nas sociedades modernas.

\section{METODOLOGIA}

De acordo com Gil (2010, p.8) "o método é o caminho para se chegar a um determinado fim", sendo, portanto, instrumento fundamental na pesquisa científica. Dessa 


\section{A DINÂMICA DO CONHECIMENTO NA CONSTRUÇÃO DE UMA UNIVERSIDADE EMPREENDEDORA: POTENCIALIDADES E FRAGILIDADES OBSERVADAS NA UNIVERSIDADE FEDERAL DE

forma, para viabilizar este estudo qualitativo, utilizou-se a técnica de análise de dados a partir da análise argumentativa de Toulmin (2001) aplicada nos estudos de Santos (2013) e Lacerda (2015). Nessas pesquisas, foram identificados aspectos institucionais e os argumentos de potencialidades e fragilidades - que repercutem na construção de uma universidade empreendedora - atinentes às relações institucionais entre a UFPE e os projetos estruturadores de desenvolvimento de Pernambuco.

Conforme Gaskell (2013, p. 65), o objetivo da pesquisa qualitativa "é uma compreensão detalhada das crenças, atitudes, valores e motivações, em relação aos comportamentos das pessoas em contextos sociais específicos”. Nesse sentido, o pesquisador visa se aproximar do objeto de estudo no intuito de fazer um mapa e entender o mundo da vida dos respondentes, além de observar as narrativas dos atores, em relação aos termos de concepção e abstratos, a fim de realizar esquemas interpretativos. A técnica propicia o levantamento de dados para "compreensão das relações sociais entre atores sociais e sua situação" relata Gaskell (2013, p. 65). Com relação ao estudo de caso, Godoy (1995) e Vergara (2013) consideram que, como tipo de pesquisa, tem o propósito de analisar intensivamente uma dada unidade social ou ambiente organizacional, com caráter de profundidade e detalhamento.

Optou-se pela técnica de Toulmin (2001), criada em 1958, por representar uma mudança no enfoque sobre as formas lógicas dos argumentos na linguagem cotidiana, estabelecendo uma anatomia dos argumentos de uso comum, uma nova teoria de argumentação, de caráter informal. A perspectiva anterior se baseava na lógica formal, fundamentada na teoria do raciocínio de Aristóteles no tocante à avaliação de um argumento.

A finalidade da utilização da análise argumentativa neste artigo foi registrar o modo como as afirmações são estruturadas dentro do discurso e avaliar sua firmeza no campo da relação institucional existente entre a UFPE e a Refinaria Abreu e Lima e na implantação do Parque Tecnológico de Fármacos e Biociências.

\section{O CASO DA UFPE}

Em pesquisas realizadas por Santos (2013) e Lacerda (2015) foi analisado o papel da UFPE e da burocracia nas parcerias estabelecidas no processo de desenvolvimento da Refinaria Abreu e Lima e na implantação do Parque Tecnológico de Fármacos e Biociências, 


\section{A DINÂMICA DO CONHECIMENTO NA CONSTRUÇÃO DE UMA UNIVERSIDADE EMPREENDEDORA: POTENCIALIDADES E FRAGILIDADES OBSERVADAS NA UNIVERSIDADE FEDERAL DE

ambos projetos industriais estruturadores de Pernambuco, tendo como pano de fundo a relação com as teorias de Evans (2004) e Etzkowitz (2009).

A pesquisa de Santos (2013, p.17) tinha o objetivo principal de "analisar como a UFPE se insere institucionalmente na estruturação da indústria de refino de petróleo em Pernambuco". Possuía ainda a finalidade de "analisar que papel de transformação industrial, com base em Evans (2004), orienta a relação entre a UFPE e a Refinaria Abreu e Lima na estruturação da indústria de refino de petróleo em Pernambuco". E, por fim, pretendia "analisar como a presença da burocracia, que orienta a relação institucional entre a UFPE e a Refinaria Abreu e Lima na estruturação da indústria de refino de petróleo em Pernambuco, contribui para o desenvolvimento dessa indústria”.

Tal estudo foi desenvolvido pelo método qualitativo, utilizando a análise argumentativa. Os achados demonstraram que a atuação da UFPE é vista nos papéis de transformação industrial demiurgo e pastor, destacando a evidência da "importância da adoção pela UFPE de um modelo de gestão com maior participação dos centros acadêmicos e da descentralização na tomada de decisões”. Segundo Santos (2013), “a Hélice Tríplice, entendida (...) através da interação universidade-governo-indústria" é visualizada "na relação entre os atores institucionais Governo do Estado de Pernambuco, UFPE e Refinaria Abreu e Lima" (SANTOS, 2013, p. 8, 104).

Em outra pesquisa, Lacerda $(2015$, p.18) teve como objeto central "analisar a importância e contribuição da UFPE na indução e implantação do Parque Tecnológico de Fármacos e Biociências de Pernambuco". Pretendia ainda "analisar como o conhecimento científico e tecnológico produzido na UFPE contribuiu no processo de formatação e na implantação do Parque Tecnológico de Fármacos e Biociências no Estado de Pernambuco". E, por fim, buscou "identificar quais características de universidade empreendedora há na UFPE".

Para o estudo foram usados método e técnica já mencionados na apresentação acima do trabalho de Santos (2013), sendo utilizadas, para levantamento dos dados, a análise de documentos e a realização de entrevistas estruturadas.

Lacerda (2015, p. 77) empregou, na análise dos resultados, a fundamentação da hipótese de Etzkowitz (2009) "identificando a importância de uma universidade na formação da hélice tríplice, tanto no aspecto de conhecimento, quanto na necessidade da universidade ter comportamento empreendedor". 


\section{A DINÂMICA DO CONHECIMENTO NA CONSTRUÇÃO DE UMA UNIVERSIDADE EMPREENDEDORA: POTENCIALIDADES E FRAGILIDADES OBSERVADAS NA UNIVERSIDADE FEDERAL DE PERNAMBUCO \\ DOI: http://dx.doi.org/10.5007/1983-4535.2016v9n4p146}

Segundo a autora (2015, p. 115): "a metodologia permitiu reconhecer a importância da UFPE no processo de indução, implantação e transferência de conhecimento", como também alcançar a finalidade da pesquisa, que é "evidenciar a importância da universidade em uma sociedade do conhecimento".

A seguir, serão sintetizados os dados encontrados nas duas pesquisas mencionadas acima, levando em consideração as potencialidades e fragilidades encontradas na UFPE para se tornar uma universidade empreendedora, assim como as relações com as teorias de Evans (2004) e Etzkowitz (2009).

\begin{tabular}{|c|c|c|}
\hline \multirow{2}{*}{$\begin{array}{c}\text { ASPECTOS } \\
\text { INSTITUCIONAIS }\end{array}$} & \multicolumn{2}{|c|}{ ARGUMENTOS DOS RESPONDENTES (SANTOS, 2013) } \\
\hline & POTENCIALIDADES & FRAGILIDADES \\
\hline $\begin{array}{l}\text { Formação oferecida pela } \\
\text { UFPE (ensino, pesquisa } \\
\text { e extensão); corpo } \\
\text { docente }\end{array}$ & $\begin{array}{l}\text { 1) Oferece cursos de graduação que fornecem formação } \\
\text { profissional nas diversas engenharias necessárias para } \\
\text { apoiar o desenvolvimento da indústria de refino de } \\
\text { petróleo, assim como de todo o Complexo Industrial } \\
\text { Portuário de Suape; } \\
\text { 2) É reconhecida como centro de formação de mão de } \\
\text { obra qualificada em diversos níveis; } \\
\text { 3) A unificação do ingresso nos cursos de engenharia é foi } \\
\text { visto como uma ação estratégica; } \\
\text { 4) Oferece eventos extracurriculares para a graduação, } \\
\text { criando uma cultura de petróleo e gás, além de } \\
\text { desenvolver tecnologias na área de refino de petróleo; } \\
\text { 5) No papel de demiurgo, verificou-se sua relevância } \\
\text { institucional ao contribuir para o desenvolvimento da } \\
\text { infraestrutura que subsidiará a indústria de refino de } \\
\text { petróleo, através da formação de recursos humanos } \\
\text { capacitados para atender as diversas demandas dos } \\
\text { empreendimentos industriais; } \\
\text { 6) Foi verificada sua forte presença nos papéis de } \\
\text { demiurgo e pastor, com uma atuação que não é estanque, } \\
\text { tendo uma vinculação entre produzir mão de obra } \\
\text { capacitada para atender as demandas de infraestrutura, } \\
\text { assim como para atuar na P\&D que apoie a estruturação } \\
\text { da indústria de refino de petróleo em Pernambuco; } \\
\text { 7) Vinculação dos cursos de graduação e de Pós- } \\
\text { Graduaça, especialmente os do Departamento de } \\
\text { Engenharia Química, para atender a demanda de mão de } \\
\text { obra especializada para o setor de refino de petróleo; } \\
\text { 8) Boa qualidade dos laboratórios de pesquisa que possui, } \\
\text { os quais apóiam a indústria de refino de petróleo; }\end{array}$ & $\begin{array}{l}\text { 1) Determinados recursos que a UFPE recebe para } \\
\text { aquisição de equipamentos para P\&D acabam sendo } \\
\text { loteados entre os professores; }\end{array}$ \\
\hline $\begin{array}{l}\text { Inovação; } \\
\text { empreendedorismo; } \\
\text { relação Universidade- } \\
\text { Indústria e burocracia }\end{array}$ & $\begin{array}{l}\text { 1) Criação do Instituto Nacional de Tecnologia de } \\
\text { Materiais (INTM), iniciativa da UFPE, com } \\
\text { financiamento da FINEP e apoio da Petrobras e do } \\
\text { Governo do Estado, visando criar na universidade um } \\
\text { centro de P\&D no setor de união de materiais, que possa } \\
\text { gerar conhecimento cientifico e apoiar empresas no } \\
\text { âmbito da inovação; } \\
\text { 2) Contribuição para perenizar o desenvolvimento ao } \\
\text { fornecer formação profissional e desenvolver atividades } \\
\text { de P\&D; }\end{array}$ & $\begin{array}{l}\text { 1) Falhas organizacionais como a existência de } \\
\text { comportamento oportunista; } \\
\text { 2) Alto grau de centralização administrativa da UFPE, } \\
\text { assim como a carência, por parte da universidade, de um } \\
\text { modelo de gestão que propicie uma melhor interação } \\
\text { universidade-indústria; } \\
\text { 3) Oportunismo na relação institucional entre a UFPE e a } \\
\text { Refinaria Abreu e Lima, decorrente em boa parte de uma } \\
\text { ineficiência burocrática; } \\
\text { 4) Deficiências na estrutura administrativa do Centro de } \\
\text { Tecnologias e Geociências (CTG). } \\
\text { 5) Dificuldades na gestão dos recursos financeiros da } \\
\text { universidade, o que prejudica o bom andamento dos } \\
\text { projetos em parceria com a indústria petroquímica. }\end{array}$ \\
\hline
\end{tabular}

Quadro 01 Relação institucional entre a UFPE e a Refinaria Abreu e Lima.

Fonte: elaborado pelos autores, a partir de Santos (2013). 


\section{A DINÂMICA DO CONHECIMENTO NA CONSTRUÇÃO DE UMA UNIVERSIDADE EMPREENDEDORA: POTENCIALIDADES E FRAGILIDADES OBSERVADAS NA UNIVERSIDADE FEDERAL DE

\begin{tabular}{|c|c|c|}
\hline \multirow{2}{*}{$\begin{array}{c}\text { ASPECTOS } \\
\text { INSTITUCIONAIS }\end{array}$} & \multicolumn{2}{|c|}{ ARGUMENTOS DOS RESPONDENTES (LACERDA, 2015) } \\
\hline & POTENCIALIDADES & FRAGILIDADES \\
\hline $\begin{array}{l}\text { Formação oferecida pela UFPE } \\
\text { (ensino, pesquisa e extensão); } \\
\text { corpo docente }\end{array}$ & $\begin{array}{l}\text { 1) Reconhecida por seu elevado grau de } \\
\text { excelência; } \\
\text { 2) Pesquisas têm focado as áreas tidas como } \\
\text { estratégicas para o Estado e para a região; } \\
\text { 3) Forte protagonismo e esforços de } \\
\text { professores-pesquisadores. }\end{array}$ & $\begin{array}{l}\text { 1) Não há obrigatoriedade de disciplinas } \\
\text { relevantes, como a de empreendedorismo; } \\
\text { 2) Presença de distorções entre o ensino e } \\
\text { as demandas do mercado; }\end{array}$ \\
\hline $\begin{array}{l}\text { Inovação; empreendedorismo; } \\
\text { relação Universidade-Indústria } \\
\text { e burocracia }\end{array}$ & $\begin{array}{l}\text { 1) Incubação de empresas foi decisivo para } \\
\text { gerar em Pernambuco o quinto pólo de } \\
\text { biotecnologia do Brasil; } \\
\text { 2) Por meio da transferência de conhecimento e } \\
\text { de ações empreendedoras, induziu a criação do } \\
\text { Parque de Fármacos e Biociência através da } \\
\text { incubadora Positiva, do NUPIT - SG (Núcleo } \\
\text { de Pesquisa e Inovação Terapêutica Suely } \\
\text { Galdino) e do Departamento de Biofísica; } \\
\text { 3) O empreendedorismo da instituição é } \\
\text { reconhecido, ao passo que tenta responder aos } \\
\text { desafios da sociedade, saindo da sua zona de } \\
\text { conforto e partindo para vislumbrar soluções } \\
\text { inovadoras; } \\
\text { 4) Através da Diretoria de Inovação e } \\
\text { Empreendedorismo (DINE), é a número um do } \\
\text { Norte e Nordeste em número de depósito de } \\
\text { patentes } \\
\text { 5) A expertise extraída da UFPE e colocada a } \\
\text { disposição do mercado, por meio do } \\
\text { empreendedorismo dos professores- } \\
\text { pesquisadores, reflete na formação de vetores, a } \\
\text { partir da transferência de conhecimento, sendo } \\
\text { revertida para a economia. }\end{array}$ & $\begin{array}{l}\text { 1) Apresenta tímidas ações } \\
\text { empreendedoras, no que concerne ao } \\
\text { incentivo ao empreendedorismo } \\
\text { estudantil, especialmente em relação às } \\
\text { empresas juniores; } \\
\text { 2) Há um longo caminho a ser percorrido } \\
\text { para que a UFPE se torne uma } \\
\text { universidade plenamente empreendedora, } \\
\text { com uma estrutura organizacional eficaz, } \\
\text { haja vista as falhas e ineficiências na } \\
\text { burocracia; } \\
\text { 3) Estrutura deficiente da Diretoria de } \\
\text { Inovação e Empreendedorismo (DINE), } \\
\text { diante da dificuldade de infraestrutura e } \\
\text { do reduzido quantitativo de pessoal; } \\
\text { 4) Ausência de um trabalho de pós- } \\
\text { incubação; } \\
\text { 5) Falta de uma política institucional forte } \\
\text { e bem estruturada que favoreça a } \\
\text { colaboração entre os stakeholders e } \\
\text { reforce a hélice tríplice; } \\
\text { 6) Falta de autonomia financeira da } \\
\text { Diretoria de Inovação e } \\
\text { Empreendedorismo (DINE); } \\
\text { 7) Inexistência de portfólio de patentes da } \\
\text { UFPE quanto à transferência de } \\
\text { conhecimento; } \\
\text { 8) Dificuldade de ver o que foi } \\
\text { transferido, os royalties que voltaram para } \\
\text { a UFPE e o impacto social; } \\
\text { 9) Dificuldades com indicadores, sendo } \\
\text { necessária uma estrutura que permita } \\
\text { rapidamente identificar os produtos saídos } \\
\text { da UFPE. }\end{array}$ \\
\hline
\end{tabular}

Quadro 02 Relação institucional entre a UFPE e o Parque Tecnológico de Fármacos e Biociências de Pernambuco.

Fonte: elaborado pelos autores, a partir de Lacerda (2015).

\section{CONSIDERAÇÕES FINAIS}

Ao ensaiar a dinâmica do conhecimento na construção de uma universidade empreendedora, pretendeu-se demonstrar, através das constatações de estudos empíricos realizados na UFPE, que a transformação da sociedade moderna é conduzida por avanços tecnológicos a partir do processo da comunicação e da informação, que traz no seu bojo um elemento básico, o qual permite uma constante inovação. Esse elemento é o conhecimento. 


\section{A DINÂMICA DO CONHECIMENTO NA CONSTRUÇÃO DE UMA UNIVERSIDADE EMPREENDEDORA: POTENCIALIDADES E FRAGILIDADES OBSERVADAS NA UNIVERSIDADE FEDERAL DE PERNAMBUCO \\ DOI: http://dx.doi.org/10.5007/1983-4535.2016v9n4p146}

Dessa maneira, tanto as instituições privadas como as públicas se voltam cada vez mais a esse fim, com diversos interesses. Dada essa condição, o Estado e, consequentemente, a burocracia têm papel fundamental nessas mudanças, demandando cada vez mais capital humano capacitado a produzir e preparado a conviver com as conquistas científicas. Assim se caracteriza a sociedade do conhecimento. Diante desse contexto, pois, a universidade é um elemento chave por socializar o conhecimento. Também é a fonte permanente da inovação, devendo acoplar de forma estratégica as suas atividades de ensino, pesquisa e extensão o elemento do empreendedorismo.

Com relação ao Estado, esse deve estar atento ao processo de transformação econômico-social globalizado, enxergando que não pode jamais se manter distante de tais aspectos. Dessa forma, é fundamental que a sociedade participe da vida econômica do estado. Nessa direção, fundamenta-se a tríplice hélice, na qual o interesse pelo conhecimento/inovação une universidade, indústria e governo. E, ao mesmo tempo, visualizase a importância da burocracia no papel ativo desta relação, evidenciando que esta não pode estar insulada.

Tais inferências e indagações teóricas são observadas, de forma apurada, nas pesquisas realizadas na UFPE por Santos (2013) e Lacerda (2015), por meio empírico, vindo a constatar a importância das teorias de Etzkowitz (2009) e Evans (2004), bem como ressaltar que o conhecimento é o principal elemento dessas transformações.

Quanto às potencialidades, constatou-se, em relação à formação oferecida pela UFPE (ensino, pesquisa e extensão) e corpo docente que a instituição é reconhecida como centro de excelência e busca alinhar de forma estratégica seus cursos e corpo técnico/científico ao desenvolvimento dos novos polos econômicos do Estado e as demandas desse mercado, especialmente os de refino de petróleo e de biociências. Além da melhoria da infraestrutura acadêmica, verificou-se uma melhoria na parte de pesquisas, com um forte protagonismo dos professores-pesquisadores. Em contrapartida, tanto na pesquisa de Santos (2013) como na de Lacerda (2015), foram relatadas várias fragilidades que denotam uma burocracia com importantes deficiências e mediana inserção na IFES estudada.

Essa deficiência no modelo de gestão e na estrutura organizacional cria condições burocráticas desfavoráveis a instituição no que se refere ao aumento de seu protagonismo nos campos da inovação e do empreendedorismo, pois há disfunções burocráticas que dificultam extrair a plenitude de seu potencial quanto à gestão de recursos humanos, materiais e 
financeiros. Em outro diapasão, apesar de haver novas estruturas administrativas aparentemente inovadoras e empreendedoras na UFPE, como a DINE (Diretoria de Inovação e Empreendedorismo), nota-se que deficiências de pessoal, falta de autonomia financeira e mesmo falhas organizacionais semelhantes a outros setores da instituição as tornam menos efetivas no alcance de seus objetivos.

Tal realidade remonta à afirmação de Lacerda (2015, p. 116): “qualquer transformação de uma sociedade passa pelo conhecimento" e aqui acrescentamos a necessidade iminente de uma gestão eficiente, eficaz e efetiva desse conhecimento, além de uma ação sistêmicoorganizacional, particularmente no âmbito das IFES. Esse elemento crucial, que foi ponto de partida deste artigo, no qual se verificou toda a sua trajetória de importância e influência é, portanto, o principal insumo e produto dos avanços da sociedade contemporânea capitaneada por uma IFES. Isso, por sua vez, impacta na UFPE em sua forma empreendedora e exige dela uma política institucional, um modelo de burocracia inserida e uma articulação com o Estado que potencializem o conhecimento produzido em seu interior, implicando o aumento de seu protagonismo no papel de participação no contexto local da hélice tríplice.

\section{REFERÊNCIAS}

ABRUCIO, F. L. Os avanços e os dilemas do modelo pós-burocrático: a reforma da administração pública à luz da experiência internacional recente. In: PEREIRA, L. C. B.; SPINK, P. K. (Org.). Reforma do Estado e Administração Pública Gerencial. Tradução Carolina Andrade, Rio de Janeiro: FGV, 2006. p. 173-199.

AUDY, J. Entre a tradição e a renovação: os desafios da universidade empreendedora. In: AUDY, J. L. N.; MOROSINI, M. C. (Org.). Inovação e empreendedorismo na universidade. Porto Alegre: EDIPUCRS, 2006. 461 p.

AUDY, J.; FERREIRA, G. C. Universidade empreendedora: A visão da PUCRS. In: AUDY, J. L. N.; MOROSINI, M. C. (Org.). Inovação e empreendedorismo na universidade. Porto Alegre: EDIPUCRS, 2006. 461 p.

ANGELONI, M. T. (Org.). Organizações do conhecimento: infraestrutura, pessoas e tecnologias. São Paulo: Saraiva, 2003. 150 p.

BAUMGARTEN, M.; TEIXEIRA, A. N.; LIMA, G. Sociedade e conhecimento: novas tecnologias e desafios para a produção de conhecimento nas Ciências Sociais. Sociedade e Estado. Brasília, v. 22, n. 2, p. 401-433, maio/ago. 2007.

BESSA, V. C.; NERY, M. B.; TERCI, D. C. Sociedade do conhecimento. São Paulo em Perspectiva. São Paulo, 17(3-4): 3-16, 2003. Disponível: 
BORGES, M. A. G. A informação e o conhecimento como insumo ao processo de Desenvolvimento. Revista Ibero-americana de Ciência da Informação (RICI). Brasília, v.1 n.1, p.175-196, jul./dez. 2008.

CALLE, G. A. D.; SILVA, E. L. Inovação no contexto da sociedade do Conhecimento. Revista Textos de la Cibersociedad. España, n.8, 2008.

CARTONI, D. M. Gestão do conhecimento como ferramenta de estratégia organizacional. Revista de Ciências Gerenciais. Valinhos, SP. v. 10, n. 12, p. 96-105, 2006.

CARVALHO, I. C. L.; KANISKI, A. L. A sociedade do conhecimento e o acesso à informação: para que e para quem ?. Revista Ciência da Informação. Brasília, v. 29, n. 3, p. 33-39, set/dez. 2000.

CASADO, F. L.; SILUK, J. C. M.; ZAMPIERI, N. L. V. Universidade empreendedora e desenvolvimento regional sustentável: proposta de um modelo. Rev. Adm. UFSM, Santa Maria, v. 5, Edição Especial, p. 633-650, dez. 2012.

CASSIOLATO, J. E. A economia do conhecimento e as novas políticas industriais e tecnológicas. In: LASTRES, M. M.; ALBAGLI, S. (Orgs.). Informação e globalização na era do conhecimento. Rio de Janeiro: Campus, 1999. p. 164-190.

CASTELLS, M. A economia informacional, a nova divisão internacional do trabalho e o projeto socialista. Cad. CRH. Salvador, v. 5 (17): p. 5-34, 1992.

CASTELLS, M. A sociedade em rede. IN: Castells, M. (org). A era da Informação: Economia, Sociedade e Cultura. Tradução: Alexandra Lemos, Catarina Lorga e Tânia Soares. $4^{\mathrm{a}}$ ed. Lisboa: Fundação CalousteGulbenkian, 2011. 713 p.

CASTELLS, M.; CARDOSO, G.A Sociedade em Rede - do conhecimento à ação política. In:Castells, M.; Cardoso (org). A Sociedade em Rede: do Conhecimento à Política. Belém: Imprensa Nacional - Casa da Moeda, 2005. p. 17-30.

CHOO, C. W. A organização do conhecimento: como as organizações usam a informação para criar significado, construir conhecimentos e tomar decisões. Tradução Eliana Rocha. $2^{\mathrm{a}}$ ed. São Paulo: Editora Senac São Paulo, 2006. 421 p.

COELHO, E. M. Gestão do conhecimento como sistema de gestão para o setor público. Revista do Serviço Público. Brasília, v. 1, n. 2, p. 89-155, 2004.

DAVENPORT, T. H.; MARCHAND, D. A. (Org.) Dominando a Gestão da Informação. Tradução Carlo Gabriel Porto Belli e Carlos Alberto Silveira Netto Soares. Porto Alegre: Bookman, 2004. 402 p. 
DAVENPORT, T. H.; PRUSAK, L. Conhecimento empresarial: como as organizações gerenciam o seu capital intelectual. Tradução de Lenke Peres. Rio de Janeiro: Campus, 1998. $237 \mathrm{p}$.

DRUCKER, P. F. A sociedade pós-capitalista. Tradução de Nivaldo Montingelli Jr. São ROSSINI Paulo: Pioneira Thomson Learning, 2002. 186 p.

EVANS, P. B. Autonomia e parceria: Estados e transformação industrial. Tradução: Christina Bastos Tigre; revisão técnica e prefácio Paulo Bastos Tigre. - Rio de Janeiro: Editora UFRJ, 2004. 402 p.

ÉSTHER, A. B. As Competências Gerenciais dos Reitores de Universidades Federais em Minas Gerais: a Visão da Alta Administração. Cadernos EBAPE.BR, v. 9, Edição Especial, artigo 10, Rio de Janeiro, Jul. 2011.

ETZKOWITZ, H. Hélice tríplice: universidade-indústria-governo: inovação em ação. Tradução: TRADUZCA. Porto Alegre: EDIPUCRS, 2009. 207 p.

GASKELL, G. Entrevistas individuais e grupais. IN: BAUER, M. W.; GASKELL, G. (Org). Pesquisa qualitativa com texto, imagem e som: um manual prático. Tradução: de Pedrinho A. Guareschi. 11 ed. Petrópolis, RJ.: Vozes, 2013. p. 64-89

GIL, A. C. Métodos e técnicas de pesquisa social. 6a ed. São Paulo: Atlas, 2010. 200 p.

GODOY, A. S. Pesquisa qualitativa: tipos fundamentais. RAE. São Paulo, [online]. v. 35, n. 3, p. 20-29, Mai-Jun., 1995.

GORDON, C. Posfácio. In: TERRA, J. C. C. Gestão do conhecimento: o grande desafio empresarial: uma abordagem baseada no aprendizado e na criatividade. São Paulo: Negócio editora, 2001. p. 241-242.

GORZ, A. O imaterial: conhecimento, valor e capital. Capital humano. Tradução de Celso Azzan Júnior. / André Gorz. São Paulo: Annablume, 2005. 107 p.

LACERDA, A, R. S. Parque Tecnológico de Fármacos e Biociências de Pernambuco: uma análise da importância da UFPE na indução e na implantação. Recife, 2015. Dissertação (Mestrado em Gestão Pública) - Universidade Federal de Pernambuco, CCSA, 2015. 130 folhas.

MEDEIROS, P. H. R.; GUIMARÃES, T. A. A institucionalização do Governo eletrônico no Brasil. Revista de Administração de Empresas-eletrônica, São Paulo, v. 46, n. 4,p. 66-78, 2006.

MOTA, T. L. N. G. Interação universidade-empresa na sociedade do conhecimento: reflexões e realidade. Ciência da Informação. Ci. Inf. [online]. Brasília, v. 28, n. 1, p. 79-86. jan. 1999. Mensal. Instituto Brasileiro de Informação em Ciência e Tecnologia-IBICT. 
NETO, A. S.; Teixeira, A. A. Sociedade do conhecimento e ciência. Perspect. ciênc. inf., Belo Horizonte, v.11 n.2, p. 220 -232, mai./ago. 2006.

NONAKA, I.; TAKEUCHI, H. A criação do conhecimento na empresa. Como as empresas japonesas geram a dinâmica da inovação. Tradução de Ana Beatriz e Priscilla Martins Celeste. Rio de Janeiro: Elsevier, 1997. 358 p.

PEREIRA, R. M. et al. Funções de confiança na gestão universitária: a dinâmica dos professores-gestores na Universidade Federal de Viçosa. Revista Gestão Universitária na América Latina - GUAL, Florianópolis, p. 260-281, fev. 2015.

PROBST, G.; RAUB, S.; ROMHARDT, K. Gestão do conhecimento: os elementos construtivos do sucesso. Tradução de Maria Adelaide Carpigiani. Porto Alegre: Bookman, 2002. 286 p.

ROSSINI, A. M.; PALMISANO, A. Administração de sistemas de informação e a gestão do conhecimento. São Paulo: Thomson, 2003. 160 p.

SANTANA, F. F.; MAIA, L. C. G. Gestor Universitário e Competências Gerenciais: do Perfil, Formação e Atuação. Encontro Nacional de Pós-Graduação e Pesquisa em Administração, XXXVIII EnANPAD - Rio de Janeiro - RJ, set. 2014.

SANTOS, L. A. S. Uma análise da relação institucional entre a Universidade Federal de Pernambuco e a Refinaria Abreu e Lima. Recife, 2013. Dissertação (Mestrado) Universidade Federal de Pernambuco. CCSA. Gestão Pública. 129 folhas.

SARAIVA, L. A. S. Cultura organizacional em ambiente burocrático. RAV, v. 6 n. 1, Curitiba. Jan./Abr. 2002.

SENGE, P. M. A quinta disciplina: arte e prática da organização que aprende. Tradução OP traduções; consultoria Zumble Aprendizagem Organizacional. 21. ed. Rio de Janeiro: BestSeller, 2006. 443 p.

SILVA, S. L. Informação e competitividade: a contextualização da gestão do conhecimento nos processos organizacionais. Ciência da Informação. São Paulo. v. 31, n. 2, p. 142-151, maio/ago. 2002.

SILVA, K. A.; CORREIA, A. E. G. C. e LIMA, I. F. O conhecimento e as tecnologias na sociedade da informação. Rev. Interam. Bibliot. Medellín (Colombia) Vol. 33, No. 1 enerojunio, 2010.

SORDI, J. O. Administração da informação: fundamentos e práticas para uma nova gestão do conhecimento. São Paulo: Saraiva, 2008. 185 p.

SOUZA, C. S. O ensino superior no quadro do processo de Bolonha. IN: AUDY, Jorge L. N.; MOROSINI, Marília C. (Org). Inovação e Empreendedorismo na Universidade. Porto Alegre: EDIPUCRS, 2006. 
SVEIBY, K. E. A nova riqueza das organizações: gerenciando e avaliando patrimônio de conhecimento. Tradução de Luiz Euclydes Trindade Frazão Filho. Rio de Janeiro: Campus, 1998. $260 \mathrm{p}$.

STEWART, T. A. Capital intelectual: A nova vantagem competitiva das empresas; tradução de Ana Beatriz Rodrigues. Priscilla Martins Celeste. Rio de Janeiro: Campus, 1998. 237 p.

TODESCAT, M.; SANTOS, N.Universidade e a EAD na sociedade do conhecimento: contemporaneidade organizacional. [S.L., s. ed.] p. 1-7, fev. 2006.

TOSTA, H. T. et al. Gestores universitários: papel e competências necessárias para o desempenho de suas atividades nas universidades federais. Revista GUAL, Florianópolis, v. 5, n. 2, p. 01-15, ago. 2012.

TOULMIN, Stephen Edelston. Os usos do argumento. São Paulo: Martins Fontes, 2001.

VERGARA, S. C. Projetos e relatórios de pesquisa em administração. 14a. ed. - São Paulo: Atlas, 2013. 94 p.

WERTHEIN, J. A sociedade da informação e seus desafios.Ci. Inf., Brasília, v. 29, n. 2, p. 71-77, maio/ago. 2000. 